\title{
Apresentação do Dossiê: Práticas, políticas e discursos no campo da saúde mental
}

Practices, policies and discourses in the mental health field

Ana Paula Müller de Andrade, Érica Quinaglia Silva, Fernanda Martinhago e Marcelo Rossal

\section{(2) OpenEdition \\ 12 Journals}

Edição electrónica

URL: http://journals.openedition.org/aa/5777

DOI: 10.4000/aa. 5777

ISSN: 2357-738X

Editora

Programa de Pós-Graduação em Antropologia Social (UnB)

\section{Edição impressa}

Paginação: 24-27

ISSN: 0102-4302

Refêrencia eletrónica

Ana Paula Müller de Andrade, Érica Quinaglia Silva, Fernanda Martinhago e Marcelo Rossal, «Apresentação do Dossiê: Práticas, políticas e discursos no campo da saúde mental», Anuário Antropológico [Online], v.45 n.2 | 2020, posto online no dia 27 maio 2020, consultado o 27 abril 2021. URL: http://journals.openedition.org/aa/5777 ; DOI: https://doi.org/10.4000/aa.5777

\section{(9) $\odot \Theta \Theta$}

Anuário Antropológico is licensed under a Creative Commons Atribuição-Uso Não-Comercial-Proibição de realização de Obras Derivadas 4.0 International. 


\title{
Apresentação do Dossiê: práticas, políticas e discursos no campo da saúde mental
}

\author{
Practices, policies and discourses in the mental health field
}

\begin{abstract}
Ana Paula Müller de Andrade • Universidade Estadual do Centro-Oeste - Brasil
Psicóloga, doutora em Ciências Humanas pela Universidade Federal de Santa Catarina. Professora do Departamento de Psicologia da Universidade Estadual do Centro-Oeste, campus Irati-PR. Pesquisadora do Instituto Nacional de Ciência e Tecnologia Brasil Plural.
\end{abstract}

\section{Érica Quinaglia Silva • Universidade de Brasília - Brasil}

Professora na Universidade de Brasília. Doutora em Antropologia pela Sorbonne e Universidade Federal de Santa Catarina, com pós-doutorado em Bioética, Ética Aplicada e Saúde Coletiva pela Universidade Federal do Rio de Janeiro, Fiocruz, Universidade Federal Fluminense e Universidade do Estado do Rio de Janeiro. Bolsista de Produtividade em Pesquisa do Conselho Nacional de Desenvolvimento Científico e Tecnológico.
ORCID: $\odot \odot \odot \odot-\odot \odot \odot 2-16 \odot \odot-\odot 8 \odot 1$ anamullerdeandrade@gmail.com

ORCID： $\odot 000-0001-9526-7522$ equinaglia@yahoo.com.br

Fernanda Martinhago • Universidade Federal de Santa Catarina - Brasil / Université Paris 8 - França

Psicóloga, mestre em Saúde Coletiva e doutora em Ciências Humanas pela Universidade Federal de Santa

Marcelo Rossal • Universidad de la República - Uruguai

Licenciado, mestre e doutor em Antropologia pela Universidad de la República. Professor adjunto na Facultad de Humanidades y Ciencias de la Educación da Universidad de la República. Integrante do Sistema Nacional de Investigadores de Uruguay (Nível 1). 
Estamos (ou ao menos deveríamos estar) todas/os em isolamento social. Quem não está em casa ou já foi a óbito ou está na linha de frente da saúde, incluída aí a saúde mental, e dos serviços essenciais que garantem nossa subsistência. Essas são as recomendações das autoridades sanitárias no Brasil e da Organização Mundial de Saúde. Confinadas/os em nossas casas em razão das ameaças de um vírus que em sua versão renovada nos impede de respirar, percebemos os efeitos subjetivos provocados por tais circunstâncias. O ar rarefaz, o coração acelera, os pensamentos se agitam, a boca seca, uma "bola" se produz na região abdominal, o sono desaparece ou, então, o torpor se estabelece, o humor oscila e, no mais das vezes, desencadeia sentimentos de tristeza e preocupação, o pensamento se embaralha e um estado catatônico se instala. Esses são alguns efeitos subjetivos da pandemia que têm circulado nas redes sociais e nas redes de profissionais que têm dado suporte às pessoas em casa ou em seus ambientes de trabalho. Eles podem ser apreendidos de diferentes maneiras, a depender do modelo interpretativo, do contexto sociocultural, político, econômico e moral em que se apresentam. O modelo hegemônico define como ansiedade, depressão, síndrome do pânico, mas, pela literatura antropológica do campo da saúde, reconhecemos que existem outras maneiras de defini-los. Talvez fossem definidos como mal-estar, aflição, agonia, quebrante, mau agouro, nervos e tantos outros modos. Com isso, argumentamos aqui que a produção do/no campo da saúde mental é plural e dinâmica.

Como parte do campo mais amplo da saúde, o da saúde mental é constituído por políticas, práticas e discursos que interrogam constantemente a realidade e por ela são interrogados. Questiona sobre o estatuto dos sujeitos, sobre as concepções de saúde, de adoecimento - sofrimento - aflição, bem como sobre outros aspectos que o permeiam. As aproximações e as contribuições entre os campos da antropologia e da saúde, em especial da saúde mental, têm ampliado as possibilidades de compreensão dos fenômenos neles produzidos. Regimes de verdade, modos de subjetivação, experiências sociais, práticas culturais e institucionais são problematizados de diferentes maneiras à luz das teorias antropológicas e do exercício etnográfico. De todas as possibilidades de apreensão do campo da saúde mental, este dossiê apresenta resultados de pesquisas que abordam as ações do Estado, como os processos de institucionalização e/ou desinstitucionalização da loucura, as redes de atendimento e as lógicas presentes em serviços de saúde mental, que comportam, por um lado, políticas pretensamente universais e, por outro, mecanismos discricionários em seus modos desiguais de distribuição de direitos. Abarca, ainda, as estratégias de sujeitos e coletividades para vivenciar e agenciar o processo de saúde-adoecimento mental, os agenciamentos sociais, os saberes locais e os discursos que tomam lugar nos distintos contextos em que tais sujeitos constroem suas experiências.

Os artigos que compõem o dossiê apresentam uma crítica ao saber psiquiátrico hegemônico e aos efeitos deste saber na materialização, em especial, das instituições de confinamento, custódia e isolamento social dos sujeitos tidos como loucos e/ou desviantes. Neste momento de distanciamento social e confinamento doméstico, as reflexões apresentadas nos alertam sobre os efeitos adversos desen- 
cadeados por esse saber-poder. De contextos de confinamento e custódia, emergem mulheres silenciadas e invisibilizadas. Das experiências extra-hospitalares, como em um Centro de Atenção Psicossocial e em um local denominado Hotel da Loucura, onde se busca articular arte e loucura, surgem prescrições, medicamentosas e morais, que visam normalizar os sujeitos. Entretanto, por meio do diálogo com os sujeitos que produzem e são produzidos por tais contextos, percebemos o alerta sobre a possibilidade de produção de estratégias de resistências e mesmo de sobrevivência para este momento. Entramos em contato com Rosa, Lúcia, Vera e outras mulheres e homens que, a partir de suas experiências, nos ajudam a vislumbrar possibilidades de existência mesmo em contextos difíceis.

\section{Contextos de confinamento, isolamento e custódia}

Três trabalhos apresentam reflexões sobre hospitais psiquiátricos, Lares Abrigados e hospitais de custódia e tratamento psiquiátrico. No texto intitulado "Por dentro do Hospital Colônia Santana: uma leitura etnográfica de prontuários psiquiátricos de mulheres internas nas décadas de 1940 e 1950”, Sônia Maluf, Mirella Britto, Inaê Barbosa e Camila Dias mostram como realizaram pesquisa em arquivos e encontraram - além de prontuários, livros de registros e outros documentos reveladores dos saberes e morais vigentes entre as décadas de 1940 e 1950 no referido hospital, em Santa Catarina - os rostos de mulheres como Conceição, Isadora e Clara. As discussões apresentadas ajudam a compreender o presente.

No texto de Érica Quinaglia Silva, Beatriz Levy e Flávia Zell, intitulado "Mulheres perigosas: a dualidade desviante das loucas infratoras", as autoras mostram como as instituições de sequestro que se mantêm na nossa realidade perpetuam práticas e discursos cujos efeitos recaem especialmente sobre as mulheres categorizadas pelos saberes-poderes psiquiátrico e jurídico como "loucas infratoras". Ao analisarem processos, laudos psiquiátricos e relatórios psicossociais concernentes a mulheres internadas em um hospital de custódia e tratamento psiquiátrico no Pará, elas argumentam que esses saberes-poderes exercitam o que chamam de "futurologia" e confinam ad aeternum essas mulheres tidas como perigosas. Contudo, as autoras apontam que nas histórias de Nailde, Helena, Ana e Thaís, entre outras, é possível encontrar agenciamentos, traduzidos na vigilância crítica delas ante a desumanidade do referido hospital-presídio.

No texto "A vida social de moradores permanentes de um Hospital psiquiátrico e asilar", Sabrina Sarto argumenta que, apesar de o referido Lar Abrigado, localizado em São Paulo, apresentar características próprias de uma instituição total, as mulheres e os homens que vivem ali mostram que suas experiências são capazes de abrir brechas, fissuras que permitem ouvir "música quente" e fazer pequenas escolhas cotidianas.

\section{Efeitos da política nacional de saúde mental}

Os outros três artigos que compõem este dossiê apresentam contextos produzidos no que poderíamos reconhecer como efeitos de uma mudança na política pública de saúde mental no Brasil e da execução de uma reorientação da assis- 
tência psiquiátrica no país. Colabora para essa discussão o texto de Felipe Magaldi, intitulado "O Hotel da Loucura: etnografia de uma política pública de saúde mental no município do Rio de Janeiro", no qual o autor discute as principais tensões entre as propostas de humanização da saúde mental, mediante serviços substitutivos de atenção psicossocial, e os conhecimentos e práticas hegemônicos da psiquiatria biomédica, estabelecidos na articulação entre a psicofarmacologia, a indústria farmacêutica e as políticas públicas. Segundo ele, a coexistência desses saberes e fazeres não implica em uma convivência pacífica, evidenciando a permanência de uma relação assimétrica entre as diferentes lógicas presentes no contexto investigado.

No texto intitulado "Poder, discursos e práticas políticas: processos de mediação em um Centro de Atenção em Araraquara", Luiz Ricardo Prado apresenta como a política nacional de saúde mental impactou práticas e discursos dos familiares de usuários de um serviço de atenção psicossocial. $\mathrm{O}$ autor argumenta que no contexto investigado foi possível reconhecer um processo de mediação cultural entre o projeto ético-político do serviço e os familiares, sendo o discurso biomédico inculcado a estes últimos.

O último texto, intitulado "Agenciamentos sociais e ações do Estado: Parada do Orgulho Louco no Brasil", de Ana Paula Müller de Andrade, discute os agenciamentos sociais e suas articulações com as ações do Estado, na sua dimensão legislativa, bem como suas repercussões nas possibilidades de consolidação das transformações culturais em relação à loucura, por meio da Parada Gaúcha do Orgulho Louco.

\section{Final aberto}

No início desta apresentação, mencionamos nosso estado atual de confinamento em meio a uma pandemia que rapidamente se alastrou por quase todos os pontos da Terra. $\mathrm{O}$ acontecimento está em pleno andamento e não sabemos quando e como findará essa pandemia, nem o isolamento que progressivamente se instaura, mas começamos a duvidar da fortaleza de nossos direitos básicos de liberdade individual e autonomia pessoal, além do acesso à saúde e da manutenção da própria vida, os quais defendemos, particularmente em relação ao modelo hegemônico do saber-poder biomédico exercido especialmente no campo da saúde mental. Nossos direitos humanos podem ser encurralados pela legitimidade de novas formas de biopoder que levam o confinamento do hospital para o lar e são exercidas até mesmo pela vigilância com técnicas que permitem a rastreabilidade da vida e dos cuidados de saúde dos sujeitos, como está acontecendo em diferentes partes do mundo por meio do uso de tecnologias de comunicação (a Coreia do Sul é um exemplo paradigmático).

Diante de uma distopia sinistra, despontam regimes de subjetivação e ressignificação da realidade, como atestam, em outra conjuntura, os textos que apresentamos neste dossiê. A etnografia persistirá no intuito de entender e desembaraçar as complexas tramas destes contextos de crise para poder enfrentá-los e defender a diversidade de expressões humanas. 